www.jmscr.igmpublication.org

Impact Factor (SJIF): 6.379

Index Copernicus Value: 71.58

ISSN (e)-2347-176x ISSN (p) 2455-0450

crossref DOI: https://dx.doi.org/10.18535/jmscr/v6i5.148

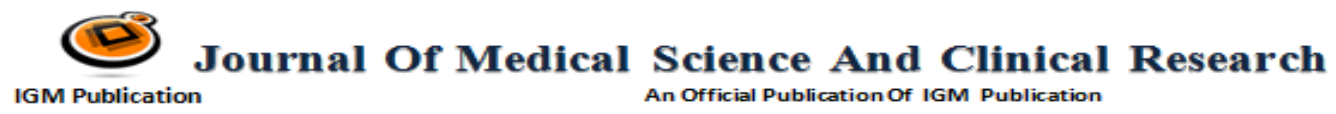

\title{
A prospective Study of Idiopathic Familial Hyperphosphatasia "Juvenile Paget's Disease" guide line of support diagnosis plus managements with different modalities of treatments depend on improvement criteria
}

\author{
Author \\ Ahmed Alkhuzai FICMS \\ Faculty of Medicine Sulaimani University/Iraq
}

\begin{abstract}
Background: Idiopathic Hyperphosphatasia (IFH, also known as juvenile Paget's disease) is a rare genetic bone disease characterized by very high bone turnover and progressive bony deformity. Treatment by different medical modalities Have advantages to control this disease, as Inhibitors of bone resorption, plus suppression of bone turnover.

Aim of Study: We assess the clinical, diagnostic criteria, plus evaluation of treatment of this rare condition with different modalities of conservative and required surgical procedures. Advantages in control these diseases and prevention the development of deformity and disability, were evaluated on improvement criteria.

Materials and Methods: A prospective descriptive study was performed on five cases of Familial Idiopathic Hyperphosphatasia, patients in the study A; 10 years age, from Baghdad B; also, from Baghdad, the sister of patient $A, 7$ years age, $C ; 8$ years age girl from Anbar, $D ; 11$ years girl from Wasit, $E ; 9$ years age boy from Sulaimaniyah. They were from Different Cities of Iraq. Presented with progressive deformities, progressive hearing loss deafness, cranial enlargement, teeth loss, long bone fractures. Also, with diagnostic radiological changes plus biochemical abnormalities, in form persistent elevated ALK. Alkaline Phosphatase, PTH Parathyroid Hormone, with drop in Vitamin D3 level. Also, they have bone biopsy change. These criteria with different treatment modalities improved the diagnosis plus managements. We have different treatment modalities; Synthetic Calcitonin, Bisphosphonate, Sodium Etidronate, pamidronate, cholcalciferol. We used the Synthetic Calcitonin therapy daily 100mg once daily as conservative preventive measure, plus cholcalciferol. The surgical Orthopaedic treatment in form fixation of the fractures when happen, Stapling of Epiphysis as Hemiepiphyseal Stapling for Knee joint correction of the deformities in Children for prevention the progressiveness of long bone deformity. We used Calcitonin injection therapy, plus cholcalciferol, was given to arrest progression of the skeletal deformities of the disease. Growth and development, pure tone audiometry, biochemistry, radiology, densitometry (DXA), and bone histology were monitored.

Results: All patients with FIH cases were treated by Calcitonin subcutaneous injection of $100 \mathrm{mg}$ daily as subcutaneous injection, therapy was given over 6 months with continuous follow up until skeletal maturity. Treatment was well tolerated, and the biochemical markers of bone turnover suppressed to within the ageappropriate normal range After 3 consecutive months. Improvement Criteria; Child become more ActiveLess Irritable, Can't Sit Without Assistance, Formation of Discrete Cortex in Long Bones, Drop Level of Alkaline Phosphatase, Inhibition of Osteocytic Osteolysis Leading to Normal Lamellar Bone. The plasma
\end{abstract}


ALP activity was suppressed to 295 U/liter, with continue to drop down continuously. However, before treatment the level was 480-677 U/L for these five patients. Radiography before treatment, there were marked spinal osteoporosis with vertebral biconcavity and a marked upper thoracic kyphoscoliosis. There was little improvement in vertebral shape, but no crush fractures occurred, also there was some progression of thoracic kyphosis for all cases without significant value. However, they had no further fractures occurred over the 3-yearsperiod happen during treatment, and all five IFH Idiopathic Familial Hyperphosphatasia remained mobile and active during performing daily activities, with improvement in skeletal development, plus preventing progressiveness of long bone deformities.

Conclusions: We have concluded that subcutaneous daily injectable Calcitonin therapy treatment can efficiently prevent the development of deformity, and disability, plus improvement in the hearing in children efficiently with IFH, also improvement in general condition, the child become more active, the dose of subcutaneous daily injectable Calcitonin therapy greater than usual doses were used in pediatric bone disease, with no adverse effects, in particular on bone mineralization.

Keywords: IFH; Idiopathic Familial Hyperphosphatasia, juvenile Paget's disease, bisphosphonates.

\section{Introduction}

Idiopathic Familial Hyperphosphatasia: (IFH) or juvenile Paget's disease is a rare autosomal recessive bone disorder commonly associated with deletion of, or mutations in, TNFRSF11B, the gene encoding osteoprotegerin $(\mathrm{OPG})^{1,2}$. Idiopathic Hyperphosphatasia' (IFH, also known as juvenile Paget's disease) the bone disorder characterized by very high bone turnover and progressive bony deformity. Inhibitors of bone resorption have been used to suppress bone turnover in the short term. deletion of, or mutations in, TNFRSF11B, the gene encoding osteoprotegerin $(\mathrm{OPG})^{1,2,3}$.

Other Names of the disease they Used; Juvenile Paget's Disease, Familial Idiopathic Hyperphosphatasia, Osteo-ectasia with Hyperphosphatasia, Hyperostosis Corticalis, Childhood Osteitis Deformans, Hereditary Bone Dysplasia with Hyperphosphatasemia.

Affected children are normal at birth, but develop a generalized, high turnover bone disease of varying clinical severity. Mildly affected subjects have relatively little bone deformity, normal growth, and maintain normal mobility throughout life, but more commonly, the bone disease results in debilitating deformity of the long bones, severe vertebral osteoporosis, short stature, skull enlargement, and deafness. The most severely affected children may never attain mobility, whereas others are relatively normal in early life but in later childhood develop deformity that rapidly progresses during adolescence $^{2}$. The clinical course of the
Hyperphosphatasia disease are same, the Inhibitors of bone resorption have been given to patients with IFH for the fact to suppress bone turnover, as preventive measure the progressiveness of deformity. In the short term, both calcitonin and bisphosphonate use have been associated with improvements in some clinical features, plus radiographic appearances, and biochemical markers of bone turnover can be suppressed ${ }^{3-13}$.Calcitonin decreases the plasma level of calcium through 3 main mechanisms: 1) Inhibition of ionized calcium absorption from intestines, 2) Inhibition of calcium reabsorption in renal tubule, 3) Inhibition of osteoclasts activity ${ }^{4,14}$. Calcitonin is a hormone formed by parafollicular cells (so-called C-cells) of the thyroid gland. From the chemical point of view, it is a 32-amino acid long peptide and the whole molecule determines its biological activity. By an alternative splicing of its gene another peptide is formed termed CGRP (calcitonin gene related peptide). The half-life of calcitonin is about 10 minutes ${ }^{14}$. These children when reach 22-26-yearold had also sustained two long bone fractures. these different types of treatments modalities will improve the disease, prevent progression of the deformity, decrease rate of fractures ${ }^{3-14}$.

Genetic Heterogeneity In Juvenile Paget's Disease, when examined TNFRSF11B using leukocyte DNA and assayed levels of osteoprotegerin and soluble osteoclast differentiation factor which is present in the serum from two young women of this disease, one from a non consanguineous American family ${ }^{3}$, 
and one from an unrelated Albanian family. Both were treated as relatively mild juvenile Paget's disease. No other known gene neighboring TNFRSF $11 B$ was absent or had portions deleted. Genome Scan analysis of the deleted genomic DNA (GenBank accession number NT_023811) indicate the existence of other potential gene in this region composed of four exons containing open-reading frames and appropriate dinucleotide splice signals bracketing the exons. However, analysis involving the Basic Local Alignment Search Tool (BLAST) failed to show any substantial similarities, suggesting that this hypothetical gene is not expressed $^{15}$.

\section{Materials and Methods}

A prospective descriptive study was performed on five cases of Familial Idiopathic Hyperphosphatasia, these patients in the study, the first one (A), 10 years age girl from Baghdad, second one 8 years old boy also from Baghdad, the third and fourth are sibling, 7years age old boy from Kut city (C) third one, 8 years old age girl from Kut city (D) sibling the fourth one, fifth one 11 years boy from Sulaimaniyah city (E), they Were from different Cities of Iraq. They Presented with progressive deformities, progressive hearing loss deafness, cranial enlargement, teeth loss, long bone fractures. Also, with diagnostic radiological changes; Normal Epiphysis, No Discrete Cortex in Long Bone, Wide Medullary Cavity, Bowing, Osteopenia, Thickened Calvarial Cortex with Craniostenosis, Coxa Vara, Micro or Macro Fractures. The Biochemical abnormalities (in form persistent elevated ALK. Alkaline Phosphatase, PTH Parathyroid Hormone, with drop in Vitamin D3 level. These disease patients have bone biopsy changes; Woven Trabecular Bone, Extremely High Bone Turnover, Demineralization with low Cancellous Bone Volume, Absence of Hyper Nucleated Osteoclasts (characteristic of Paget's diseases).Also, all five cases Presentation of FIH diseases; Expanding Hyperostotic long bones with progressive deformities, persistently elevated serum alkaline phosphatase, Skeletal pain with swelling, Episodic hypercalcemia, Early hypercalcemia, Early onset deafness, Premature tooth loss. Also, all five child patients had begun walking at the usual age (1-2 years). However, begun to develop gait abnormalities, the long bone become deformed. Plus, kyphoscoliosis from the age of 6 years, the upper thoracic kyphoscoliosis was more, the spine noted to be markedly osteopenic with widespread "codfish" deformities. A Dexa Scan showed marked spinal osteopenia, with a lumbar spine a real BMD with the score indicates the SDs below normal range. These deformities become marked with progressive bone deviation during childhood development, until the age of 16 years, the vertebral bodies developed collapse, with severe pelvic and flat bone weakness of the acetabular bone, the pubic, iliac, and the ischial bone until acetabular protrusion happen. which were associated with sever type of sensorineural deafness, these criteria with different treatment modalities will improved the diagnosis, then support treatment method. We have different treatment medical modalities; We used the Synthetic Calcitonin 100 intl units subcutaneously or intramuscularly once time daily until improvement clinically, also the biochemical markers corrected, treatment will continue for 6 months. Calcitonin together with calciferol, because of the plasma level of vitamin D3. The function of Calcitonin, decreases the plasma level of calcium through Three main mechanisms: 1 . Inhibition of ionized calcium absorption from intestines, 2. Inhibition of calcium reabsorption in renal tubule, 3. Inhibition of osteoclasts activity. The surgical Orthopaedic treatment in form fixation of the fractures when happen with different types of fixation accordingly, Stapling of Epiphysis Hemiepiphyseal Stapling for Knee joint correction of the deformities in Children for prevention the progressiveness of long bone deformity. 


\section{JMSCR Vol||06||Issue||05||Page 934-943||May}
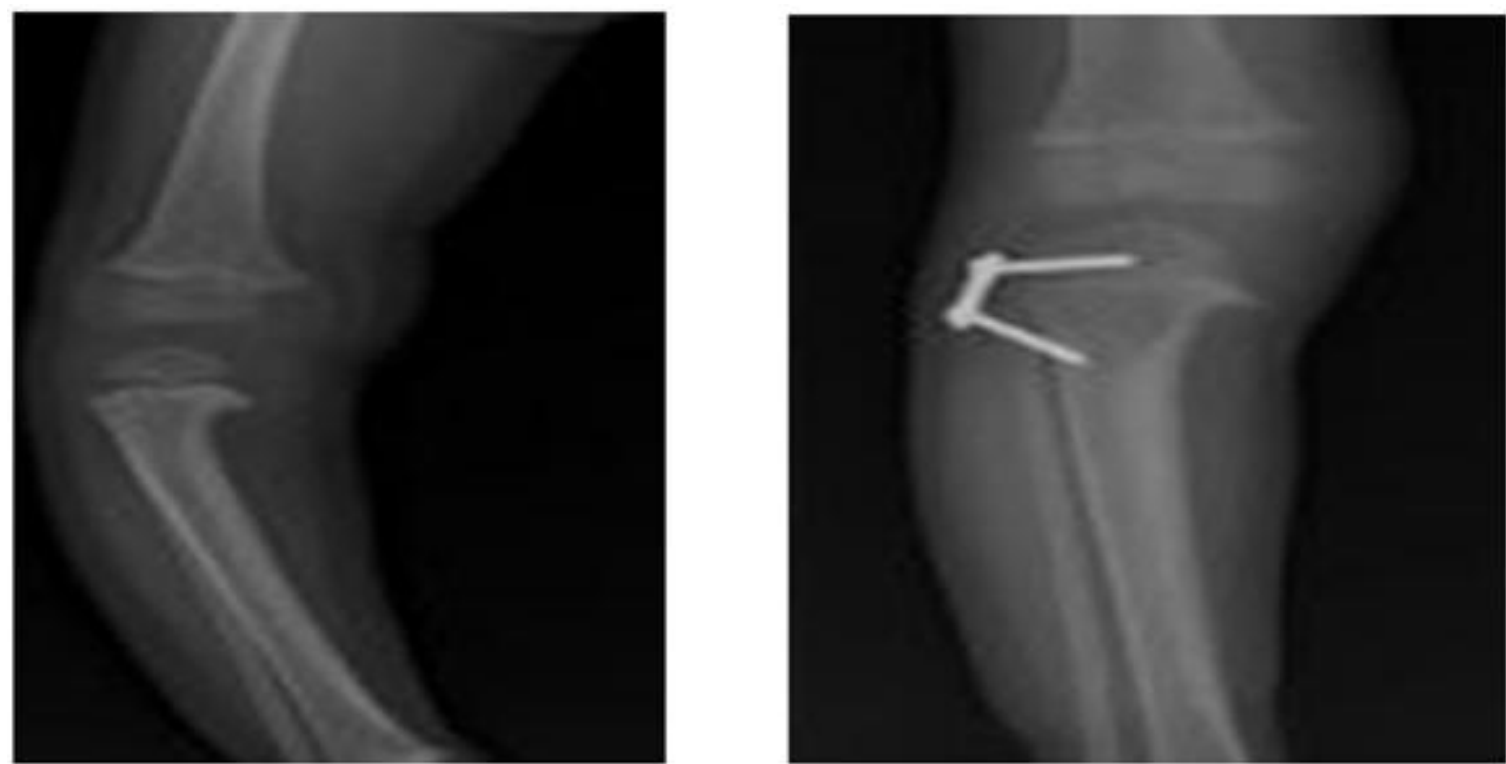

Fig.1: Preoperative- Postoperative Genu Varum/ Hemiepiphysiodesis Hemiepiphyseal stapling

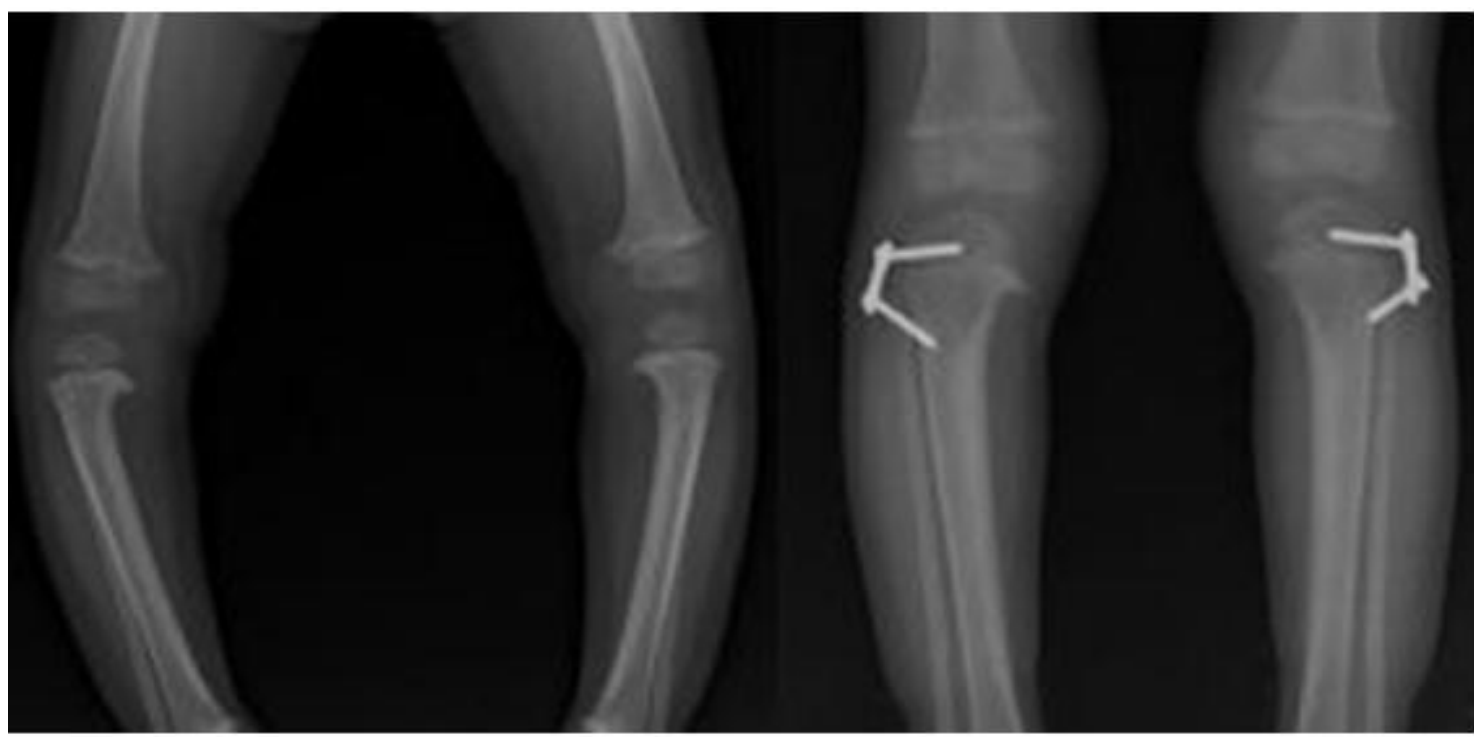

Fig.2: Bilateral Stapling Epiphysis Hemiepiphyseal stapling Correction Bilateral Genu Varum

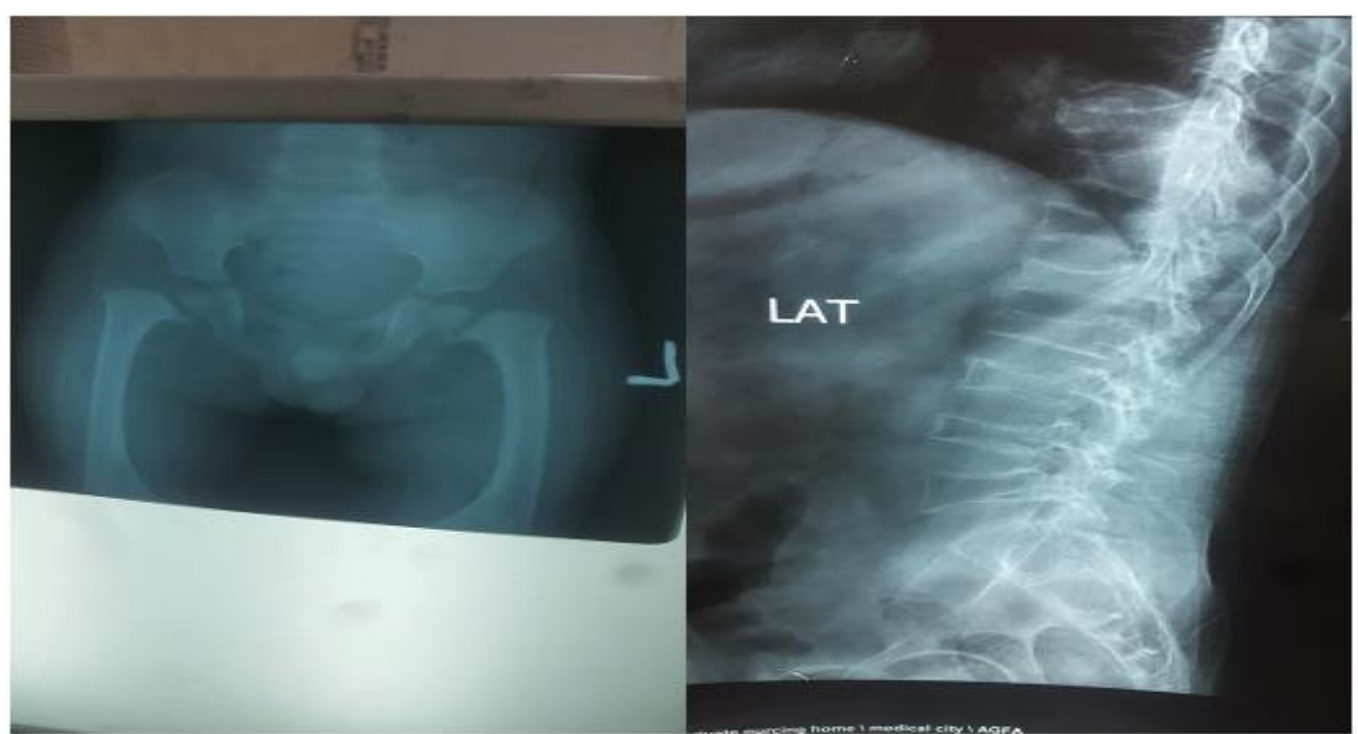

Fig.3: Bilateral Coxa Vara Hip Joint Deformity+ Spine X- Ray like Codfish Vertebrae 


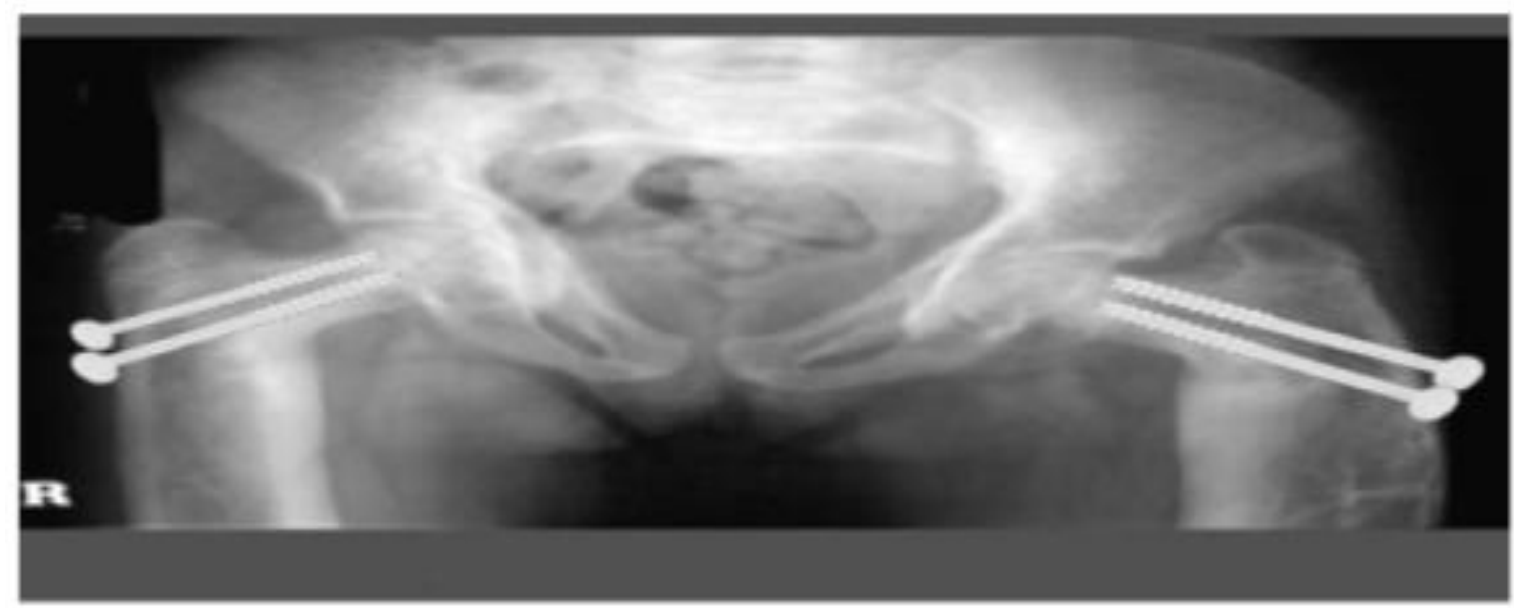

Fig. 4: Pelvic X- Ray Bilateral Prophylactic Fixation All five cases Presentation of FIH diseases have, swelling, Episodic hypercalcemia, Early Expanding Hyperostotic long bones with hypercalcemia, Early onsetdeafness, Premature progressive deformities, persistently elevate of tooth loss. serum alkaline phosphatase, Skeletal pain with

\section{Finding Supporting the Diagnostic Criteria in the Clinical Presentation}

Characteristic finding shows in the tables;

Table.1: IFH Idiopathic Familial Hyperphosphatasia long Bone

\begin{tabular}{|c|c|c|c|c|c|}
\hline Long Bone & Case A & Case B & Case C & Case D & Case E \\
\hline Deformities & + & + & + & + & + \\
\hline Fractures & + & + & + & + & + \\
\hline Osteopenia & + & + & + & + & + \\
\hline Coxa Vara & + & + & + & + & + \\
\hline
\end{tabular}

Table.2: IFH/ Idiopathic Familial Hyperphosphatasia / Skeletal

\begin{tabular}{|c|c|c|c|c|c|}
\hline Skeletal & Case A & Case B & Case C & Case D & Case E \\
\hline Pain & + & + & + & + & + \\
\hline Swelling & + & + & + & + & + \\
\hline Scoliosis & + & + & + & + & + \\
\hline
\end{tabular}

Table 3: IFH/ Idiopathic Familial Hyperphosphatasia/Cranial

\begin{tabular}{|l|c|c|c|c|c|}
\hline Cranial & Case A & Case B & Case C & Case D & Case E \\
\hline Enlargement & + & + & + & + & + \\
\hline Reduce Base of Skull & + & + & + & + & + \\
\hline Brain Compression & - & - & - & - & - \\
\hline Reduce Intracranial space & - & - & + & + & + \\
\hline Chiari I malformation & - & - & - & - & - \\
\hline
\end{tabular}

Table.4: Familial Idiopathic Hyperphosphatasia / Otological

\begin{tabular}{|l|c|c|c|c|c|}
\hline Otological & Case A & Case B & Case C & Case D & Case E \\
\hline Hearing Loss & + & + & + & + & + \\
\hline Thick T.M Tympanic Membrane & + & + & + & + & + \\
\hline Thick Middle Air Mucosa & + & + & + & + & + \\
\hline Rigid Immobile Ossicular Chain & - & - & + & + & + \\
\hline Expansion of Calvarial Bones & + & + & + & + & + \\
\hline
\end{tabular}


Table: 5 Familial Idiopathic Hyperphosphatasia/ Dental

\begin{tabular}{|c|c|c|c|c|c|}
\hline Dental & Case A & Case B & Case C & Case D & Case E \\
\hline Teeth Deformities & + & + & + & + & + \\
\hline Tooth loss & + & + & - & - & + \\
\hline
\end{tabular}

Table 6: Familial Idiopathic Hyperphosphatasia/ Biochemical

\begin{tabular}{|l|l|l|l|l|l|}
\hline Biochemical & Case A & Case B & Case C & Case D & Case E \\
\hline Elevated ALK. Alkaline Phosphatase & + & + & + & + & + \\
\hline Elevated Uric Acid & - & - & - & - & - \\
\hline Elevated Calcium \& Phosphate & - & - & - & - & - \\
\hline Parathyroid PTH & + & + & - & + & - \\
\hline Vit. D3 & + & + & + & + & + \\
\hline Osteocalcin & - & - & - & - & - \\
\hline Renal Functions & - & - & - & - & - \\
\hline
\end{tabular}

Table.7: Familial Idiopathic Hyperphosphatasia/ Radiological

\begin{tabular}{|l|c|c|c|c|c|}
\hline Radiological Finding & Case A & Case B & Case C & Case D & Case E \\
\hline Normal Epiphysis & + & + & + & + & + \\
\hline $\begin{array}{l}\text { Formation of Discrete } \\
\begin{array}{l}\text { Cortex in Long } \\
\text { BonesLeading to } \\
\text { Normal Lamellar Bone }\end{array}\end{array}$ & + & + & + & + & + \\
\hline $\begin{array}{l}\text { Wide Medullary } \\
\text { Cavity }\end{array}$ & + & + & + & + & + \\
\hline$\quad$ Bowing & + & + & - & + & - \\
\hline Osteopenia & + & + & + & + & + \\
\hline $\begin{array}{l}\text { Thickened Calvarial } \\
\begin{array}{l}\text { Cortex with } \\
\text { Craniostenosis }\end{array}\end{array}$ & + & - & + & - & + \\
\hline Coxa Vara & - & - & - & + & - \\
\hline $\begin{array}{l}\text { Micro or Macro } \\
\text { Fractures }\end{array}$ & + & + & + & - & - \\
\hline
\end{tabular}

Table.8: Familial Idiopathic Hyperphosphatasia/ Bone Biopsy

\begin{tabular}{|l|c|c|c|c|c|}
\hline Bones Biopsy & Case A & Case B & Case C & Case D & Case E \\
\hline $\begin{array}{l}\text { Woven Trabecular } \\
\text { Bone }\end{array}$ & + & + & + & + & + \\
\hline $\begin{array}{l}\text { Extremely High Bone } \\
\text { Turnover }\end{array}$ & + & + & + & + & + \\
\hline $\begin{array}{l}\text { Demineralization with } \\
\text { low Cancellous Bone } \\
\text { Volume }\end{array}$ & + & + & + & + & + \\
\hline $\begin{array}{l}\text { Absence of Hyper } \\
\text { Nucleated Osteoclasts } \\
\text { (characteristic of Paget's) }\end{array}$ & + & + & + & + & + \\
\hline
\end{tabular}

\section{Surgical management of Familial idiopathic} Hyperphosphatasia

- Epiphyseal fusion sideway preventive progression the deformity

- Fixation of fracture when happen

- Prophylactic fixation

\section{Results}

All five patients with FIH cases were treated by Calcitonin subcutaneous injection of $100 \mathrm{mg}$ daily as subcutaneous injection, therapy was given over 6 months with continuous follow up until three years. Treatment was well tolerated, no major side effect, and the biochemical markers of bone turnover suppressed to within, the age-appropriate normal range After 3 consecutive months. Improvement 
Criteria; Child become more Active- Less Irritable, Can't Sit Without Assistance, Formation of Discrete Cortex in Long Bones, Drop Level of Alkaline Phosphatase, Inhibition of Osteocytic Osteolysis Leading to Normal Lamellar Bone. the plasma ALP activity was suppressed to $295 \mathrm{U} /$ liter, with continue to drop down continuously, before treatment the level was 480-677 U/L for these five patients. Severe hypocalcemia did not develop for these patients. Radiography before treatment, there were marked spinal osteoporosis with vertebral biconcavity and a marked upper thoracic kyphoscoliosis. There was little improvement in vertebral shape, but no crush fractures occurred, also there was some progression of thoracic kyphosis for all cases without significant value. However, they had no further fractures occurred over the 3-year period happen during follow up treatment, and all five IFH Idiopathic Familial Hyperphosphatasia remained mobile and active during performing daily activities, with improvement in skeletal development, plus stoppage progressiveness of long bone deformities. Radiographs showed improvement in spinal osteopenia and cortical bone dimensions and arrest of progressive acetabular protrusion with stoppages these progression in acetabular ring. The long bones, treatments were associated with increases in cortical thickness, plus deformity didn't progress. There were no side effects and no change in hematological parameters for hepatic or renal function. Puberty proceeded normally, and menarche were reached at the age of 12. The patient was short at presentation, they grow $6.4 \mathrm{~cm}$, In the first year of therapy grow 4.1 , then they grow $2.2 \mathrm{~cm}$ in the second and third years. In the pelvis, there was no progression of the early acetabular protrusion, present before treatment, there will be stoppages of these progression in acetabular ring. A significant recovery of hearing, before treatment showed moderate to severe deafness, which is improved After 3 years of treatment in hearing mostly at low frequencies, during assessment in the pre treatment \& post treatment times. The head circumference remained unchanged over the 3 years, just above the 98th percentile for age. The histology; Transiliac bone biopsy specimens were undertaken before treatment therapy, also post therapy again 32 months later. Both biopsy specimens showed signs of very high bone turnover in the first biopsy with extensive formation and resorption surfaces., woven osteoid, and marrow fibrosis.

Table.9: Characteristic presentation of FIH (Familial Idiopathic Hyperphosphatasia)

\begin{tabular}{|l|c|c|c|c|c|}
\hline Characteristic Presentations/ Diagnostic Criteria & Case A & Case B & Case C & Case D & Case E \\
\hline Diagnostic Radiological changes & + & + & + & + & + \\
\hline Progressive Long Bone deformities & + & + & + & + & + \\
\hline $\begin{array}{l}\text { Biochemical Persistently Elevated Serum ALK. } \\
\text { Alkaline Phosphatase }\end{array}$ & + & + & + & + & + \\
\hline $\begin{array}{l}\text { Responses to Treatment (Calcitonin, Intensive } \\
\text { Bisphosphonate Therapy) }\end{array}$ & + & + & + & + & + \\
\hline Bone Biopsy & + & + & + & + & + \\
\hline Otological Finding & + & + & + & + & + \\
\hline Skull Vault \& Base & + & + & + & + & + \\
\hline Skeletal Abnormalities & + & + & + & + & + \\
\hline Dental Changes & + & + & - & - & + \\
\hline
\end{tabular}

Table.10: Improvement Criteria of FIH (Familial Idiopathic Hyperphosphatasia)

\begin{tabular}{|l|c|c|c|c|c|}
\hline Improvement Criteria & Case A & Case B & Case C & Case D & Case E \\
\hline Child become More Active- Less Irritable & + & + & + & + & + \\
\hline \multicolumn{1}{|c|}{ Can Sit Without Assistance } & - & - & - & - & - \\
\hline Formation of Discrete Cortex in Long Bones & - & - & - & - & - \\
\hline Drop Level of Alkaline Phosphatase & + & + & + & + & + \\
\hline $\begin{array}{l}\text { Inhibition of Osteocytic Osteolysis Leading to } \\
\text { Normal Lamellar Bone }\end{array}$ & - & - & - & - & - \\
\hline
\end{tabular}




\section{Discussion}

All five patients with FIH cases in Our finding were treated by Calcitonin subcutaneous injection of 100 mg daily as subcutaneous injection, therapy was given over $18^{\text {th }}$ months with continuous follow up until skeletal maturity. Treatment was well tolerated, and the Improvement Criteria child become more Active- Less Irritable, Can't Sit Without Assistance, Formation of Discrete Cortex in Long Bones, Drop Level of Alkaline Phosphatase, Inhibition of Osteocytic Osteolysis Leading to Normal Lamellar Bone. This is supported by other study Doyle et al, Dunn etal. They used Calcitonin treatment in IFH hereditary bone dysplasia with hyperphosphatasemia $^{3,4,5,6,7}$. The biochemical markers of bone turnover suppressed to within normal range of same age-appropriate child after 3 consecutive months. The similarities in clinical, plus other investigational data, in our study confirm the other study, Whalen , Blanco etal, were data related to IFH diseases happen in more than one family member, also the phenotype within that family is very similar, confirm that it is progress to deformities plus other change in certain body organ if left untreated, the child we describe in this report would have developed severe deformity and permanent disability like her older brother and sister $^{5,6,10,16,17}$. Our presentation, there were already long bone deformity, plus severely deteriorating of the spinal disease (supported measurement the relative shortening of the trunk), and acetabular protrusion. Skull involvement by bone causing progressive hearing loss, the auditory canal nerve compression. The rapid deterioration of deformity at puberty in high turnover bone disease is well recognized, for example, in renal osteodystrophy, this is the same clinical data in other studies ${ }^{18}$. After $18^{\text {th }}$ months of injectable therapy treatment, and 3 years of follow up, the patients (who had by this time reached adult bone age) become more active plus more mobile, and within the exception of some worsening of the upper thoracic kyphosis, however the thoracic deformities had not progressed. Bone turnover was suppressed, and there were substantial positive changes in audiometry, radiographic appearances, and densitometry, plus bone biomarkers. We believe that the Calcitonin therapy treatment of FIH will arrested the progression of severe deforming bone disease in our patients confirm in improvements criteria. The decision to use Calcitonin therapy was based on poor prognosis with pamidronate therapy, so will choose subcutaneous Calcitonin therapy in high potency and intolerance of nasal spray of Calcitonin, will be concentrated on subcutaneous injection of 100 intl unit Subcutaneous daily $18^{\text {th }}$ months, as it is the upper limit of doses given to adults for treatment of Paget's disease, the calcitonin reported 100 times more potent than pamidronate in our study, supported by Horwith, Dunn et al. Moreover, this high dose was repeated frequently until $18^{\text {th }}$ months to drop level of ALP activity as normal in same age child, plus normal range for growing children $^{3,4,5,6,7,19}$. There were no new fractures, although there was deterioration in her kyphosis. The pubertal development was normal, but the final adult stature was short. There were no obvious effects on bone histology when evaluated bone biopsy post injectable Calcitonin treatment. In particular, there was no evidence of a mineralization defect, both osteoid surface and volume were lower on the second biopsy, this reflecting the decrease bone turnover, in our study confirmation by Grauer, Rauch, and Kanis et $\mathrm{al}^{15,20,21}$. In the 3 years follow up post treatment therapy, there were clear evidence from audiometry of deterioration in hearing. Sensorineural deafness is a recognized feature of IFH in pre treatment times, compare to post treatment times in our study supported by Monsell of hearing defect with improvement post therapy during assessment times in pre and post therapy treatment $^{22}$. Our study, also support the requirements of higher dose subcutaneous injectable calcitonin, not the nasal spray, will lead to improvements in outcome results of IFH plus drop in bone turn over, this supported by Doyle, Dunn, Cassinelli et al. they suggest that not all types of pediatric bone disease that get improvements from bisphosphonate therapy when used in same dose requirements. However, that higher than 
conventional doses might be necessary to achieve this improvements ${ }^{3,4,5}$. Whereas the doses that we administered were effective, it does not mean that lower doses would not have worked or that no benefit accrued from the course, from other example of pamidronate in conventional dose that our patient had received earlier. it is clear that our treatment therapy was associated with more dramatic effects on bone turnover, bone density, bone biomarkers, radiographic appearances, and hearing. 3,4,5,7,9,23

\section{Conclusions}

We concluded that Calcitonin therapy treatment prevent the development of deformity and disability plus improvement in child mobilities, activities. Also improved the hearing in this child with IFH. The dose with higher dose than child used in childhood bone diseases, However, no side effects on the bodies of these diseased child.

\section{References}

1. Whyte MP, Obrecht SE, Finnegan PM, Jones JL, Podgornik MN, McAllister WH, Mumm S 2002 Osteoprotegerin deficiency and juvenile Paget's disease. N Engl J Med 247:175-184.

2. Chong B, Hegde M, Fawkner M, Simonet S, Cassinelli H, Coker M, Kanis J, Seidel J, Tau C, Tuysuz B, Yuksel B, Love D, Cundy T 2003 Idiopathic hyperphosphatasia: Relationships between phenotype and mutations in the gene encoding osteoprotegerin. J Bone Miner Res 18:2095-2104.

3. Doyle FH, Woodhouse NJY, Glen ACA, Joplin GF, MacIntyre I 1974 Healing of the bones in juvenile Paget's disease treated by human calcitonin. Br J Radiol 47:9-15.

4. Horwith M, Nunez EA, Krook L, Viteri F, Torun B, Mena E, Suh SM, Eisenberg E, MacIntyre I, Whalen JP 1976 Hereditary bone dysplasia with hyperphosphatasemia: response to synthetic human calcitonin. Clin Endocrinol (Oxf) 5(Suppl):341S-352S.

5. Whalen JP, Horwith M, Krook L, MacIntyre I, Mena E, Viteri F, Torun B, Nunez EA
1977 Calcitonin treatment in hereditary bone dysplasia with hyperphosphatasemia: A radiographic and histologic study of bone. Am J Roentgenol 129:29-35.

6. Blanco O, Stivel M, Mautalen C, Schajowicz F 1977 Familial idiopathic hyperphosphatasia. J Bone Joint Surg $\mathrm{Br}$ 59:421-427.

7. Dunn V, Condon VR, Rallison ML 1979 Familial hyperphosphatasemia: Diagnosis in early infancy and response to human thyrocalcitonin therapy. Am J Roentgenol 132:541-545.

8. Spindler A, Berman A, Mautalen C, Ubios J, Santini EA 1992 Chronic idiopathic hyperphosphatasia: Report of a case treated with pamidronate and a review of the literature. J Rheumatol 19:642-645.

9. Cassinelli HR, Mautelen CA, Heinrich JJ, Miglietta A, Bergada C 1992 Familial idiopathic hyperphosphatasia: Response to longterm treatment with pamidronate. Bone Miner 19:175-184.

10. Singer F, Siris E, Shane E, Dempster D, Lindsay R, Parisien M 1994 Hereditary hyperphosphatasia: 20 year follow-up and response to disodium etidronate. J Bone Miner Res 9:733-738.

11. Golob DS, McAlister WH, Mills BG, Fedde KN, Reinus WR, Teitelbaum SL, Beeki S, Whyte MP 1996 Juvenile Paget disease: Life-long features of a mildly affected young woman. J Bone Miner Res 11:132-142

12. Tu “ysu “z B, Mercimek S, Unger S, Deniz M 1999 Calcitonin treatment in osteoectasia with hyperphosphatasia (juvenile Paget's disease). PediatrRadiol 29:838-841.

13. Demir E, Bereket A, Ozkan B, Topcu M 2000 Effect of alendronate treatment on the clinical picture and bone turnover markers in chronic idiopathic hyperphosphatasia. J Pediatr Endocrinol Metab 13:217-221

14. Tuysuz B, Mercimek S, Ungur S, et al; Calcitonin treatment in osteoectasia with hyperphosphatasia (juvenile Paget's disease): 
radiographic changes after treatment.

PediatrRadiol. 1999 Nov29(11):838-41

15. Rauch F, Travers R, Plotkin H, Glorieux FH 2002 The effects of intravenous pamidronate on the bone tissue of children and adolescents with osteogenesis imperfecta. J Clin Invest 110:1293- 1299.

16. Eroglu M, Taneli NH 1976 Congenital hyperphosphatasia (juvenile Paget's disease). Ann Radiol 20:145-150.

17. Bonakdarpour A, Maldjian C, Weiss S, Roach N, Stein E 2000 Hyperphosphatasemia: Report of three cases. Eur J Radiol 35:54- 58.

18. Kanis JA, Henderson RG, Heynen G, Ledingham JGG, Russell RGG, Smith R, Walton RJ 1977 Renal osteodystrophy in nondialysed adolescents: Long-term treatment with 1 - hydroxycholecalciferol. Arch Dis Child 52:473-481.

19. Fleisch H 1995 Bisphosphonates in Bone Disease-From the Laboratory to the Patient. Parthenon Publishing, New York, NY, USA.

20. Grauer A, Heichel S, Knaus J, Dosch E, Ziegler R 1999 Ibandronate treatment in Paget's disease of bone. Bone 24(Suppl):87S-89S.

21. Kanis JA 1991 Pathophysiology and Treatment of Paget's Disease of Bone. Martin Dunitz, London, UK.

22. Monsell EM, Cody DD, Bone HG, Divine GW, Winham JP, Jacobson GP, Newman CW, Patel SC 1995 Hearing loss in Paget's disease of bone: The relationship between pure-tone thresholds and mineral density of the cochlear capsule. Hear Res 83:114-120.

23. Viereck V, Emons G, Lauck V, Frosch K-H, Blaschke S, Grundker C, Hofbauer LC 2002 Bisphosphonates pamidronate and zoledronic acid stimulate osteoprotegerin production by primary human osteoblasts. Biochem Biophys Res Commun 291:680686. 